\title{
Isolation of cowpea genes conferring drought tolerance: Construction of a cDNA drought expression library\#
}

\author{
I Gazendam* and D Oelofse \\ Biotechnology Division, Agricultural Research Council-Vegetable and Ornamental Plant Institute, Private Bag X293, \\ Pretoria 0001, South Africa
}

\begin{abstract}
The main objective of this study was to identify and isolate the genes conferring drought tolerance in cowpea. A cDNA library enriched for cowpea genes expressed specifically during responses to drought was constructed. A procedure called suppression subtractive hybridisation (SSH) was successfully employed to obtain these differentially expressed transcripts. The library consists of 4160 individual clones. Preliminary sequencing results identified two clones to be known stress-related plant genes (GST (glutathione-S-transferase) and PR-1 (pathogenesis-related protein-1)). Micro-array analysis will be performed on the library's clones to verify their differential expression during drought conditions, and to identify additional clones for further investigation. Promising genes can eventually be used to genetically engineer crops for drought tolerance to improve food security in water-stressed areas.
\end{abstract}

Keywords: cowpea, drought tolerance, suppression subtractive hybridisation (SSH)

\section{Introduction}

South Africa is classified as a water-scarce country (Department of Water Affairs and Forestry (DWAF), 2004). The utilisation of marginal soils by plants tolerant to drought stress provides the greatest potential for agricultural expansion. Drought stress is, however, a multigene trait. Therefore, breeding for tolerance must include different strategies, including gene transfer. However, in order to understand the gene networks that underlie plant stress, it is necessary to identify and characterise the genes that respond to abiotic and biotic stress.

Cowpea (Vigna unguiculata L. Walp) is indigenous to Southern Africa. Most lines are drought-tolerant and can be grown under the harshest growing conditions. It is, therefore, an important crop for subsistence and small-holder farmers (Quass, 1995).

The aim of this research project was to identify and isolate the genes conferring drought tolerance in cowpea. These identified drought-tolerant genes will be used in the transformation of crops of importance for the resource-poor farmer, leading to increased food security.

The first step in this quest, as well as in many other biological investigations, is to construct a cDNA library enriched for differentially expressed transcripts. Successful projects that followed a similar approach include the characterisation of the defence pathways in pearl millet and Fusarium wilt in banana (Van den Berg et al., 2004). This paper addresses the construction of a customised cDNA library that contains cowpea genes expressed specifically during responses to drought. A procedure called suppression subtractive hybridisation (SSH) was

\footnotetext{
Revised version. Originally presented at the International Symposium on the Nutritional Value and Water Use of Indigenous Crops for Improved Livelihoods held on 19 and 20 September 2006 at the University of Pretoria in Pretoria, South Africa

* To whom all correspondence should be addressed.

III +2712 841-9611; fax: +2712 808-1499; e-mail: igazendam@arc.agric.za
}

employed to obtain these differentially expressed transcripts (Diatchenko et al., 1996). The completed library can also serve as a valuable resource in the investigations of other characteristics of cowpea.

\section{Materials and methods}

\section{Cowpea drought trial}

A cowpea drought trial was performed in which one droughttolerant (IT96D-602) and one susceptible (Tvu7778) cowpea line were subjected to drought conditions. Physiological parameters of plant stress were measured in order to determine time points for the preparation of the drought expression library.

\section{Suppression subtractive hybridisation (SSH)}

Differential expression analysis by means of SSH (Diatchenko et al., 1996) was employed to prepare a cDNA drought expression library for cowpea. Unstressed susceptible cowpea (Tvu7778) cDNA was subtracted from drought-stressed tolerant cowpea (IT96D-602) cDNA as previously described (Van den Berg et al., 2004; Hein et al., 2004). Briefly, RNA was isolated from unstressed Tvu7778 (9 and $12 \mathrm{~d}$ ) and drought-stressed IT96D-602 (9 and 12 $\mathrm{d}$ without water) using Tri-reagent (Sigma) and PVP (Ambion's Plant RNA isolation aid). Contaminating genomic DNA was removed with the Turbo DNA-free kit (Ambion) and the RNA cleaned up with the Plant RNeasy kit (Qiagen). mRNA was isolated from $50 \mu \mathrm{g}$ pools of stressed IT96D-602 RNA (tester) and control Tvu7778 RNA (driver) using an Oligotex mRNA purification kit (Qiagen). cDNA was synthesised from mRNA using the Roche cDNA synthesis kit.

Subtractive hybridisation was performed on RsaI digested cDNA fragments using the PCR-Select cDNA subtraction kit (Clontech). Both forward and reverse subtractions were performed. After subtraction the products were amplified by a primary PCR and a nested secondary suppression PCR to generate differentially expressed cDNA fragments. 


\section{Preparation of a drought expression library}

PCR products from six individual reactions were pooled, separated on an agarose gel and DNA fragments excised in three size ranges, namely $<200 \mathrm{bp}, 200$ to $650 \mathrm{bp}$ and 650 to $1700 \mathrm{bp}$. The fragments were purified from the gel using the Qiaquick gel extraction kit (Qiagen).

Fifty nanograms of each cDNA fraction were ligated into the pGEM-T Easy Cloning Vector and transformed into Escherichia coli JM109 following the manufacturers' instructions (Promega). Transformation reactions were plated out on blue-white selection media ( $140 \mathrm{~mm} \mathrm{LB}$-agar plates containing $100 \mu \mathrm{g} / \mathrm{m} \ell$ ampicillin, spread with $20 \mu \ell \mathrm{X}-\mathrm{Gal}(50 \mathrm{mg} / \mathrm{m} \ell$ in DMF) and $50 \mu \ell$ IPTG $(0.2 \mathrm{M})$ ). The plates were incubated at $37^{\circ} \mathrm{C}$ for $16 \mathrm{~h}$ after which they were stored at $4^{\circ} \mathrm{C}$ for $24 \mathrm{~h}$. White colonies were picked, grown overnight at $37^{\circ} \mathrm{C}$ in liquid LB medium containing $100 \mu \mathrm{g} /$ $\mathrm{m} \ell$ ampicillin and stored as $25 \%$ glycerol stocks at $-70^{\circ} \mathrm{C}$ in sterile 96-well microtitre plates (Corning).

\section{Sequencing of selected clones}

Randomly selected clones of the forward subtracted library were sequenced using the SP6 and T7 primers and BLAST (Basic Local Alignment Search Tool; Altschul et al., 1990) analysis performed to identify possible drought-tolerance genes.

\section{Preparation of amplified drought expression library cDNA fragments}

Library PCR amplification: A PCR master mix, containing $1 \times$ Ammonium acetate buffer, $2.5 \mathrm{mM} \mathrm{MgCl}_{2}, 200 \mu \mathrm{M}$ dNTPs, $0.25 \mu \mathrm{M}$ each of SP6 (5'- ATT TAG GTG ACA CTA TAG -3') and T7 (5'- TAA TAC GAC TCA CTA TAG GG -3') primers, and $1 \mathrm{U}$ Biotaq DNA polymerase (Bioline) in a total volume of $100 \mu \ell$ nuclease-free water, was prepared in a sterile plastic tube. One hundred $\mu \ell$ aliquots were added to each well of a 96-well PCR plate (Thermo-Fast, ABGene). The PCR plates were inoculated with the overnight bacterial cultures of cDNA clones using a 96-pin plate replicator (Nunc). The PCR plate was sealed with a silicon mat (Corning).

PCR cycling conditions: Reactions were incubated in a PTC100 Thermocycler (MJ Research) at $94^{\circ} \mathrm{C}$ for $5 \mathrm{~min}$, followed by
30 cycles each of $94^{\circ} \mathrm{C}$ for $30 \mathrm{~s}, 50^{\circ} \mathrm{C}$ for $30 \mathrm{~s}$ and $72^{\circ} \mathrm{C}$ for $1 \mathrm{~min}$. A final elongation step of $72^{\circ} \mathrm{C}$ for 5 min was included. The PCR products were stored at $4^{\circ} \mathrm{C}$ until purification.

PCR clean-up: PCR products were cleaned up with Montage PCR purification plates (Microsep). PCR samples (100 $\mu \ell)$ were transferred to the wells of the Montage PCR purification plate, placed on a vacuum manifold (Microsep) and a vacuum of 20 inch $\mathrm{Hg}$ applied for $20 \mathrm{~min}$. The plate was blot-dried using paper towels. Fifty $\mu \ell$ of MilliQ water were applied to each well and the plate agitated for $15 \mathrm{~min}$ at $1400 \mathrm{r} / \mathrm{min}$ on an Ika-Vibrax VXR shaker (Janke \& Kunkel Typ VX1). The suspensions were transferred to a 96-well storage plate and covered with well caps (Nunc). The purified PCR products were stored in the storage plates at $-20^{\circ} \mathrm{C}$.

Stretch gel: PCR products were analysed on a $1 \%$ agarose gel in $0.5 \times$ TAE containing ethidium bromide using the ElectroFast Stretch 204 gel assembly (ABGene). Samples were loaded with $1 \times$ ReddyRun gel loading buffer (ABGene) and $3 \mu \ell(75 \mathrm{ng})$ of ElectroFast marker (ABGene) were loaded into the first lane of each row. A voltage of $100 \mathrm{~V}$ was applied for $30 \mathrm{~min}$ and the gel visualised and photographed on a UV source.

\section{Results and discussion}

\section{Cowpea drought trial}

The two cowpea cultivars IT96D-602 and Tvu7778 were chosen for this study, since previous studies had established their respective drought tolerance and susceptibility (Spreeth et al., 2004). Physiological data were collected during a drought trial, of which total leaf proline content is presented in Fig. 1.

It has previously been determined that proline content gives an indication of the level of stress experienced by a plant (Spreeth et al., 2004). Proline content increased at a slower rate and to a lower concentration in the drought tolerant line IT96D-602 than in the susceptible line Tvu7778 (Fig. 1). A lower proline content is a good indication that a plant is coping well during drought stress. IT96D-602 also showed better recovery at day 16 when re-watered.

Physiological variance accounts for the high variability

Proline content of two cowpea lines during drought trial

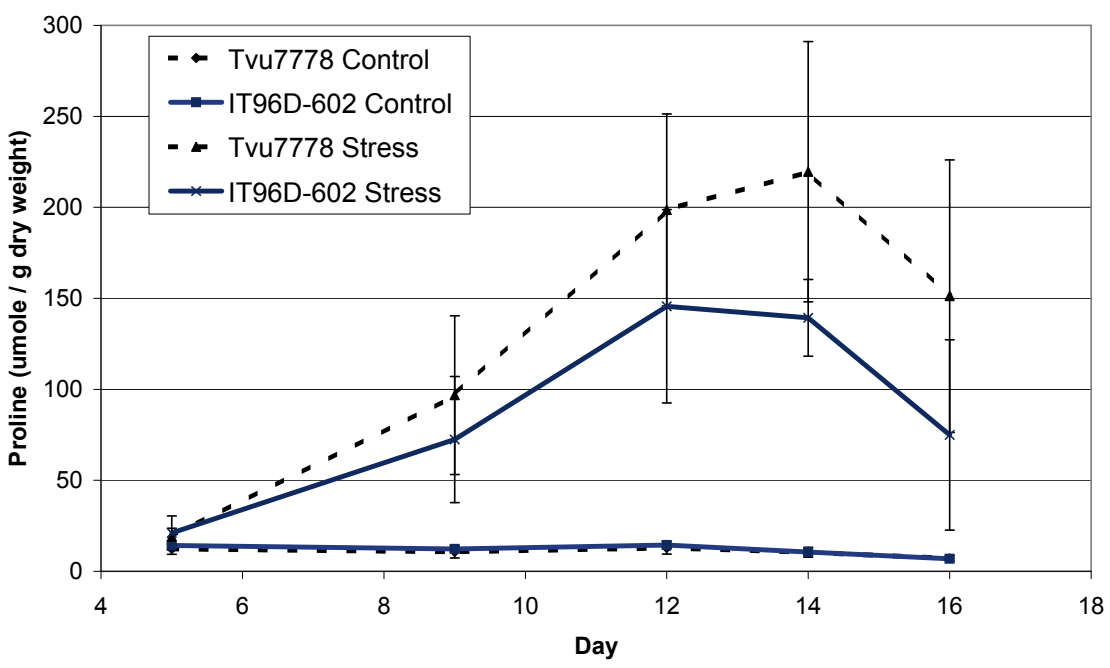

Figure 1

Proline content in $\mu$ mole per gram dry leaf weight of a susceptible (TVu7778) and a tolerant (IT96D602) cowpea line during the 16-day drought trial planted in October 2004 at the Agricultural Research Council - Vegetable and Ornamental Plant Institute (Roodeplaat). The average and standard error of five biological replicates are presented. 
observed (Fig. 1), which is characteristic of biological systems. Days 9 and 12 were chosen as the time points to isolate RNA for generation of the drought expression library.

\section{Suppression subtractive hybridisation (SSH)}

Forward and reverse subtraction of drought stressed IT96D-602 and unstressed Tvu7778 cDNA were performed. Genes that are expressed and up-regulated due to the drought tolerant phenotype, general stress responses, as well as genotypic differences between the two lines, were amplified during SSH. SSH also equalises the abundance of cDNAs in the target (Diatchenko et al., 1996), which increases the likelihood of low-copy genes (rare transcripts) being incorporated into the library.

Figure 2 presents the distinct patterns of PCR products obtained from six individual nested secondary PCRs for each of the forward and reverse subtractions (Fig. 2, lanes 1-12). The secondary PCRs were performed using separate primary PCRs as templates. Discrete bands were observed in the subtracted samples (Fig. 2, lanes 1-12, pooled together in lane 16 and 17), while the un-subtracted tester (UT) and driver (UD) PCR yielded a smear (Fig. 2, lanes 14-15). The subtracted tester (ST, Fig. 2, lane 16) refers to the forward subtraction and the subtracted driver (SD, Fig. 2, lane 17) to the reverse subtraction.

The presence of a number of distinct bands in the individual subtracted samples (Fig. 2, lanes 1-12) is an indication that the $\mathrm{SSH}$ was successful, since they represent genes that have been enriched for. A smear represents genes that weren't enriched during the $\mathrm{SSH}$ procedure.

The forward and reverse subtracted cDNA fragments, ranging from $0.1-2 \mathrm{~kb}$ in size, were cloned to produce the cDNA library.

\section{Preparation of drought expression library}

A cDNA library consisting of 44 96-well microtitre plates, containing 4160 individual clones, was generated. This library is expected to contain the genes that are involved in drought tolerance, which is an important outcome of this project.

\section{Sequencing of selected clones}

BLAST analysis was performed on the sequences of five randomly selected cowpea clones. The alignments that gave the smallest e-values corresponded to genes deposited in the BLASTX database (Table 1 - see next page).

Four out of the five selected cowpea cDNA clones coded for known genes found in a variety of plant species. Two are known to be stress-related genes (GST (Glutathione-S-transferase) and PR-1 (pathogenesis related protein-1)). Additional clones will be selected and sequenced in future.

Since cowpea is not a model plant, sequence data available on databases are limited. Therefore, only cowpea genes that are conserved in other plants of which sequence information is available, such as Arabidopsis thaliana whose genome has been sequenced, can be given identities based on their homology. However, even A. thaliana's genome is not as yet fully annotated, which, in this study, may result in the classification of an interesting clone (such as $4 \mathrm{~A} 1$ in this case) as an unknown putative protein.

\section{Preparation of amplified drought expression library cDNA fragments}

The 4160 clones were amplified by PCR and the products purified as described in the Materials and Methods. The stretch gel

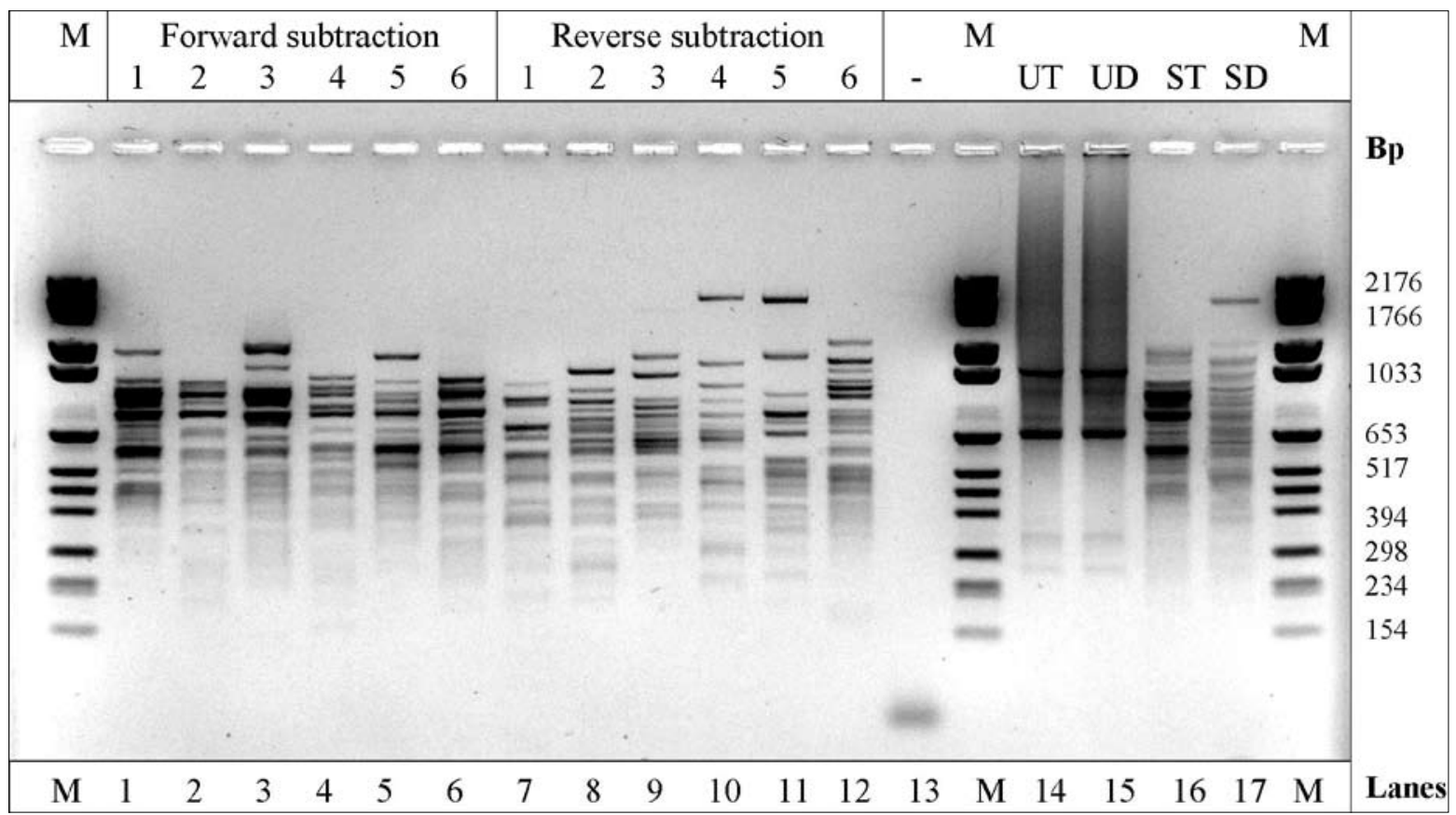

Figure 2

Secondary PCR amplification of subtracted and unsubtracted cDNA fragments produced from drought stressed IT96D-602 and unstressed Tvu7778 cowpea cultivars that had been subtracted with suppression subtractive hybridisation. M: Molecular weight marker VI (Roche; 154-2176bp). The secondary PCR products were loaded as follows: Lanes 1-6: six individual subtracted tester (ST) samples; Lanes 7-12: six individual subtracted driver (SD) samples; Lane 13: negative water control; Lanes 14-15: pooled unsubtracted tester (UT) and unsubtracted driver (UD), respectively; Lane 16-17: pooled subtracted tester (ST) and subtracted driver (SD), respectively. 
TABLE 1

Cowpea cDNA clones from the forward subtracted cowpea drought expression library sharing similarity to genes in other plant species. BLAST (Altschul et al., 1990) was used to find the matches. A smaller e-value corresponds to a higher homology.

\begin{tabular}{|l|l|l|l|l|}
\hline Clone & Putative gene & Share similarity to genes in plant species & $\begin{array}{l}\text { Best e- } \\
\text { value }\end{array}$ & $\begin{array}{l}\text { Stress- } \\
\text { related }\end{array}$ \\
\hline 2A1 & MtN19 & Pisum sativum, Medicago truncatula, Oryza sativa, Arabidopsis thaliana & $4 \mathrm{E}-73$ & $?$ \\
\hline 2A2 & GST & $\begin{array}{l}\text { Phaseolus acutifolius, Glycine max, Arabidopsis thaliana, Vitis vinifera, Citrus } \\
\text { sinensis }\end{array}$ & $9 \mathrm{E}-95$ & Yes \\
\hline 3A2 & $\begin{array}{l}\text { miraculin, } \\
\text { tumor-related } \\
\text { protein }\end{array}$ & Solanum melongena, Nicotiana tabacum & $3 \mathrm{E}-12$ & $?$ \\
\hline 3A6 & PR-1 & $\begin{array}{l}\text { Glycine max, Vitis vinifera, Arabidopsis thaliana, Brassica napus, } \text { B. juncea, } \\
\text { Nicotiana tabacum }\end{array}$ & $3 \mathrm{E}-58$ & Yes \\
\hline 4A1 & unknown protein & Arabidopsis thaliana & $5 \mathrm{E}-15$ & $?$ \\
\hline
\end{tabular}

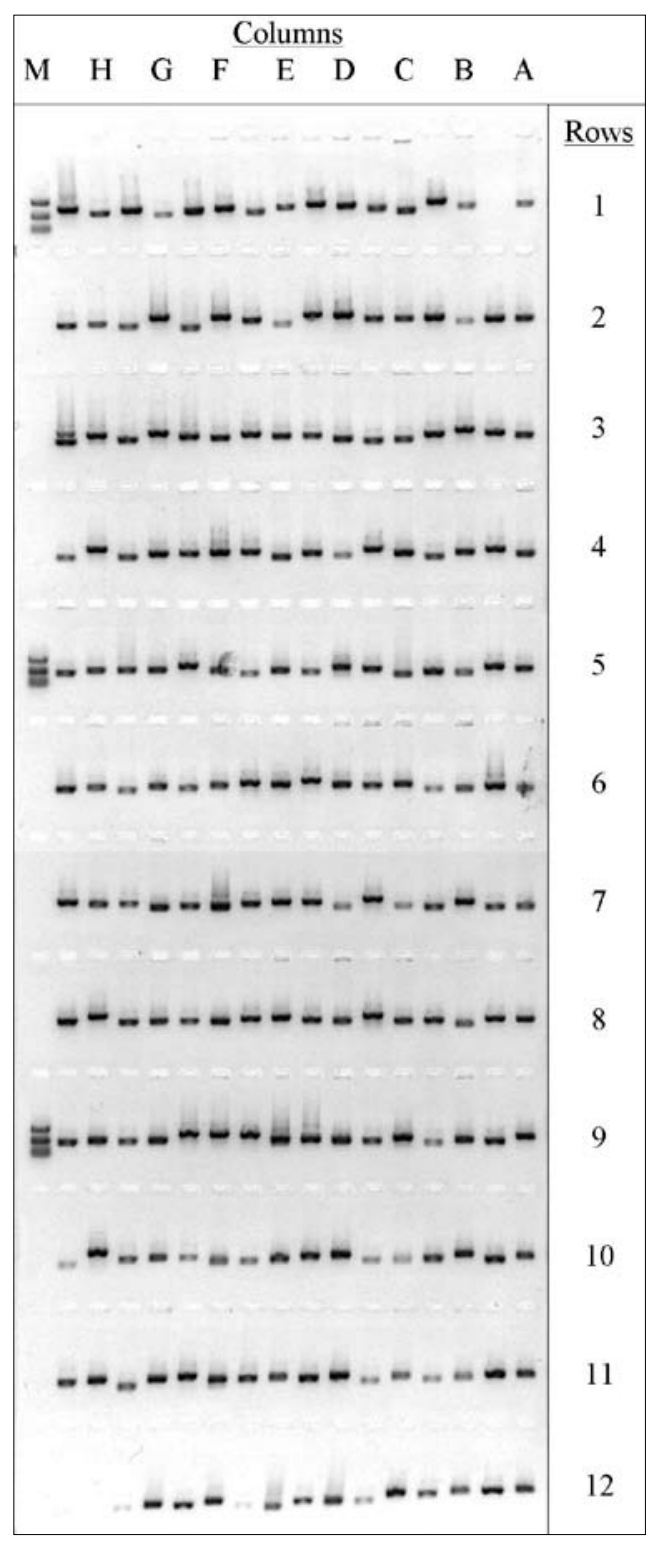

Figure 3

PCR amplification of 192 cowpea drought expression cDNA clones from library plates 17 and 18 using the SP6 and T7 primers. M: ElectroFast marker (200, 500 and 1000bp); columns

$H-A$ : columns $H$ to $A$ on the $96-$ well culture plate 18, respectively; rows 1-12: rows 1 to 12 on the 96-well culture plate, respectively. analysis of library plates 17 and 18 indicated that PCR amplification was successful for these plates and that the clones contain single inserts (Fig. 3). Purified products of plates 17 and 18 were loaded into alternating wells, since the stretch gel has a capacity for two 96-well PCR plates. All, except 317 clones from the total library, yielded PCR products with sizes between 200 bp and $1 \mathrm{~kb}$ (results not shown).

\section{Future work}

Now that the cowpea drought-response cDNA library has been generated and the fragments amplified by PCR, a number of steps will follow towards achieving the long term goal of identifying drought-tolerance genes.

Micro-array analysis will be performed on the library's clones to verify their differential expression in the two populations. This is a cutting edge technology currently performed at only two academic institutions in South Africa (The University of Pretoria and the University of Cape Town). It facilitates the investigation of expression levels of high numbers of genes or clones simultaneously. The amplified cDNA fragments will be spotted onto a micro-array slide using a high-density robotic arrayer and hybridised to labelled cDNA or RNA from different sources in order to compare their expression levels.

Expression patterns of interesting genes that emanate from the micro-array study will be investigated further by employing realtime reverse-transcription PCR on RNA samples extracted from differentially drought-treated cowpea plants.

Future objectives of this study include obtaining the fulllength sequences of promising genes by genome walking, which will enable the genetic engineering of crops grown by resourcepoor farmers for increased drought tolerance. Subsequent testing will confirm if the inserted gene(s) is effective in improving the drought tolerance of the chosen crop, leading to improved food security in water-stressed areas.

\section{Conclusion}

The first step in identifying and isolating the genes conferring drought tolerance in cowpea has been successfully completed. This was the construction of a cDNA library enriched for differentially expressed transcripts. The completed cowpea cDNA library will be a valuable resource in the investigations of drought tolerance, as well as other characteristics, of cowpea. Micro-array studies will follow to identify clones of importance during drought tolerance. 


\section{Acknowledgements}

Dr. BG Crampton (CSIR) and Prof. DK Berger (University of Pretoria, FABI) for guidance in the SSH and micro-array experiments.

\section{References}

ALTSCHUL SF, GISH W, MILLER W, MYERS EW and LIPMAN DJ (1990) Basic local alignment search tool. J. Mol. Biol. 215 403-410. DEPARTMENT OF WATER AFFAIRS AND FORESTRY (DWAF) (2004) National Water Resource Strategy (NWRS) (1 $1^{\text {st }}$ edn.). DWAF, Pretoria.

DIATCHENKO L, LAU YFC, CAMPBELL AP, CHENCHIK A, MOQADAM F, HUANG B, LUKYANOV S, LUKYANOV K, GURSKAYA N, SVERDLOV ED and SIEBERT PD (1996) Suppression subtractive hybridization: a method for generating differentially regulated or tissue-specific cDNA probes and libraries. Proc. Natl.
Acad. Sci. U.S.A. 93 6025-6030.

HEIN I, CAMPBELL EI, WOODHEAD M, HEDLEY PE, YOUNG V, MORRIS WL, RAMSAY L, STOCKHAUS J, LYON GD, NEWTON AC and BIRCH PRJ (2004) Characterisation of early transcriptional changes involving multiple signalling pathways in the Mla13 barley interaction with powdery mildew (Blumeria graminis f. sp. hordei). Planta 218 803-813.

QUASS CF (1995) Guidelines for the Production of Cowpeas. National Department of Agriculture, Pretoria, South Africa.

SPREETH MH, SLABBERT MM, DE RONDE JA, VAN DEN HEEVER E and NDOU A (2004) Screening of Cowpea, Bambara Groundnut and Amaranthus Germplasm for Drought Tolerance and Testing of the Selected Plant Material in Participation with Targeted Communities. WRC Report No. 944/1/04. WRC, Pretoria.

VAN DEN BERG N, CRAMPTON BG, HEIN I, BIRCH PR and BERGER DK (2004) High-throughput screening of suppression subtractive hybridization cDNA libraries using DNA microarray analysis. BioTechniques 37 (5) 818-824. 
Available on website http://www.wrc.org.za ISSN 0378-4738 = Water SA Vol. 33 No. 3 (Special Edition) 2007 ISSN 1816-7950 = Water SA (on-line) 